\title{
RADIOGRAFÍA DE LA SOCIEDAD COLONIAL AMERICANA A TRAVÉS DE LOS SÍNODOS DE LOS SIGLOS XVII Y XVIII
}

\author{
por \\ ENRIQUE BANDE RODRÍGUEZ
}

\section{VIDA Y COSTUMBRES DE LOS FIELES}

Los sínodos tienen mandado que todos los fieles cristianos oigan misa los domingos y fiestas de guardar y que no trabajen en obras serviles y si alguno tiene necesidad de trabajar lo ha de manifestar al obispo para que disponga lo que conviene sin que dejen de oír misa'. Los hombres libres y los amos de los esclavos que no estuvieren a más de una legua de distancia de los lugares vayan a oír misa los domingos y festivos a sus parroquias e iglesias y lleven a sus esclavos ${ }^{2}$.

\subsection{Trajes prohibidos a los hombres y mujeres}

Recomiendan los sínodos la moderación de los trajes de los hombres y de las mujeres por la mayor indecencia que resulta de la moda de traer capas cortas y todo el cuerpo casi desnudo y las mujeres las faldas y los zapatos del todo picados con grave deformidad. Les mandan a las mujeres que bajen los faldellines hasta la garganta del pie y que no usen dichos calzados con los labores picados. A los contumaces les imponen una multa de veinte y cinco pesos.

\footnotetext{
' Sínodo de Santiago de Cuba. Año 1681. Const. I, Lib. II, Tít. 10.

${ }^{2}$ Sínodo de Santiago de Cuba. Año 1681. Const. I, Lib. II, Tít. 10.

"CUADERNOS DE ESTUDIOS GALLEGOS", Tomo XLI, Fascículo 106, Santiago 1993-94.
} 


\subsection{Trajes no permitidos en las iglesias}

Los sínodos les mandan que ninguna persona de estado y condición que sea entre en la iglesia con los sombreros puestos y con estos no asistan a la celebración de la misa, y de los divinos oficios y tampoco lo hagan los deudos del difundo. Existía la costumbre de que en los entierros, honras fúnebres y cabos de año entrasen en las iglesias los familiares y herederos del difunto con las cabezas cubiertas y así estuviesen oyendo la misa. Los sínodos les mandan que cuando entren en la iglesia todos se descubran las cabezas y estén con la decencia que se debe en lugar tan sagrado bajo pena de diez ducados ${ }^{3}$. El abad exorte al sexo femenino de la gente noble de este pueblo a que no entre en las iglesias con la cabeza descubierta ni vestido de calle, por quedar al desnudo todo el cuerpo y la cintura. El sínodo sólo permite sayas y mantillas para asistir a las iglesias ${ }^{4}$.

\subsection{Ritos prohibidos en las iglesias}

No se hagan corrillos ni conversaciones en las iglesias ni en las puertas se empiecen o acaben las fiestas, ni en sus cementerios juegen a naipes ni a dados, barras, ni pelota, ni interpreten comedias profanas, ni duerman en ellas, ni en sacristías, ni den posadas en ermitas y capillas a ninguno para que en ellas duerma o coma. No se pongan pinturas indecentes en las iglesias ni en las calles por donde pasa la procesión del Corpus bajo pena de excomunión mayor y diez ducados 5 .

\subsection{Cantos prohibidos en las iglesias}

Se han introducido en las iglesias los tonos y modulaciones nuevas y profanas que desdicen de los templos pues aunque no sean impuros los versos pueden excitar. Las voces del ofertorio son las mismas tocatas que se estilan en festines y cenas profanas y por ello el sínodo manda y obliga la abstención de estas tocatas y músicas profanas aunque sean letras a lo divino y a causa también de los villancicos burlescos de los maitines de navidad ${ }^{6}$.

\footnotetext{
${ }^{3}$ Sínodo de Santiago de Cuba. Año 1654. Const. II, Lib. III, Tít. 9.

${ }^{4}$ Sínodo de Concepción de Chile. Año 1745. Const. XIII, Cap. XV.

${ }^{5}$ Sínodo de Conceción de Chile. Año 1747. Const. XII, Cap. II.

${ }^{6}$ Sínodo de Concepción de Chile. Año 1747. Const. XII, Cap. II.
} 


\subsection{Prohibición de poner altares en casas particulares}

Dado que el lugar indicado para tener los nacimientos es el templo de Dios y dado que al ponerse en las casas particulares resultan muchas indecencias y poca reverencia a las imágenes sagradas en que intervengan músicas y bailes, concurso de gente y otras indecencias los prohibimos bajo pena de excomunión mayor y diez ducados. No se prohiben los altares y nacimientos en que se pone un determinado número de velas en casas de personas virtuosas y recogidas y con la decencia debida. Allí se ha de congregar la familia a rezar el rosario y la doctrina cristiana ${ }^{7}$. Los días más sagrados de la navidad del Señor, de Santa Cruz, de San Juan Bautista y del patrono con pretexto de pía devoción se acostumbra a hacer altares en casas particulares que se profanan con el concurso de hombres y mujeres y por ello el sínodo manda que no se hagan dichos altares en las casas los días referidos sino otros ${ }^{8}$. No se prohiben los que se hacen en algunas piezas secretas sin permitir concurso de ambos sexos para que los de la familia hagan rogaciones a Dios?

\subsection{Trabajos prohibidos}

Los amos dueños de esclavos y los encomenderos en los días de fiesta no se han de ocupar ni han de ocupar a sus esclavos en obras de trabajos materiales y les impone tres reales de multa por cada vez que trabajen, alquilaren, o hicieren trabajar a sus esclavos. Las mismas penas le imponen a los labradores y personas libres que incumplan el mandato ${ }^{10}$.

También se prohiben los trabajos en casas particulares, tiendas y pulperías por transgredir el precepto de santificar las fiestas en esta ciudad no vendan cosa alguna de día ni de noche en los días de fiesta, esos días no tengan sus puertas abiertas. Si viven en las tiendas las tendrán a medio abrir. bas.

El sínodo sólo les permite vender hasta las nueve del día azúcar y hier-

Por tener los mercaderes sus tiendas abiertas hasta horas avanzadas de la noche, resultan perniciosas consecuencias para las mujeres que se pierden y se dedican a la prostitución so pretexto de comprar y por ello manda

\footnotetext{
${ }^{7}$ Sínodo de Santiago de Chile. Año 1681. Const. VII, Lib. I, Tít. 2.

${ }^{8}$ Sínodo de Concepción de Chile. Año 1747. Const. XIV, Cap. XV.

${ }^{9}$ Sínodo de Santiago de Chile. Año 1668 y 1763. Const. VII, Tít. 12.

${ }^{10}$ Sínodo de San Juan de Puerto Rico. Año 1645. Const. XIV.
} 
el sínodo que se cierren las puertas de las tiendas en verano a las $10 \mathrm{y}$ en invierno al toque de ánimas bajo pena de cuatro reales.

Por ser la embriaguez un vicio perjudicial a los indios tanto en lo espiritual como en lo temporal, ya que pierden sus caballos, espuelas, frenos y sus mismas ropas le manda el sínodo que en días de fiesta no abran las pulperías ${ }^{11}$.

\subsection{Comida y uso del tabaco en las iglesias}

Ninguna persona coma ni beba chocolate en las iglesias del obispado, ni en ellas se queden de noche mujeres con los rostros cubiertos, ni descubiertos, ni se sienten, así hombres como mujeres, en las tarimas de los altares ni chupen tabaco. Uno de los abusos que hay en este obispado es el tabaco; usando estas hierbas en las iglesias se celebran los divinos oficios y por ello el sínodo manda que dentro de las iglesias y lugares sagrados no se tome tabaco de ningún género en ningún tiempo, ni lo lleven los sacerdotes y lo usen en ningún otro lugar poco antes de decir misa por la poca reverencia y la impureza con que algunos celebran ${ }^{12}$.

En las iglesias muchas veces patente el Santísimo Sacramento se sacan cajetillas de tabaco en polvo, se toma y se convida con él. Mandamos que se evite tal abuso principalmente descubierto el Santísimo.

\subsection{Participación Sacramental}

Cualquier cristiano hombre o mujer cuando llegue a tener discrección está obligado a confesarse una vez al año y todos los señores de los esclavos y encomenderos de indios, padres de familia están obligados a entregar al párroco cédulas de como han cumplido con el precepto de la iglesia de confesarse y comulgar todos sus súbditos ${ }^{13}$.

Los decretos antiguos a los que no estaban desposados y aún después de velados les aconsejaban que no se juntasen ni cohabitasen juntos por algún tiempo y que estuviesen en continencia y oraciones. El Concilio de Trento amonesta que entretanto no estuviesen desposados no cohabiten antes de las bendiciones nupciales. El sínodo manda que de aquí en adelante se desposen y velen juntamente o que por lo menos se velen con la brevedad posible, pues hay muchos que sin haber recibido las bendiciones

\footnotetext{
"Sínodo de Concepción de Chile. Año 1747. Const. XI, Capt. XV.

${ }^{12}$ Sínodo de San Juan de Puerto Rico. Año 1645. Const. VIII.

${ }^{13}$ Sínodo de Santiago de Cuba. Año 1681. Const. XI, Lib. III, Tít. 9.
}

"CUADERNOS DE ESTUDIOS GALLEGOS", Tomo XLI, Fascículo 106, Santiago 1993-94. 
cohabitan juntos ${ }^{14}$.

Cuando un indio contrae matrimonio con una india de otro pueblo el marido está obligado a seguir el domicilio de la mujer y a cohabitar con ella ${ }^{15}$.

\subsection{Malas costumbres, amancebamientos y pecados públicos}

Dado que facilmente se pegan las malas costumbres en las gentes sencillas y rudas cuales son los indios los sínodos ordenan y mandan que en ningún caso en los pueblos o estancias donde habitaren se permitan negros ni mulatos y los párrocos no los reciban ni hospeden a hombres vagabundos ni jugadores, ni otros de mala fama y para que se eviten los pecados en que las mujeres suelen caer con facilidad y el escándalo de los recién convertidos mandan los sínodos que no puedan tener huéspedes ni parientes en sus casas más de tres días. Les imponen a los curas la obligación de visitar los navíos que lleguen a sus puertos y examinen si traen libres, criados, y mujeres de mal vivir y si hay algún amancebamiento o sospechoso en la fe los castiguen y corrijan ${ }^{16}$. Debía ser muy común el amancebamiento con mujeres casadas dado que los sínodos les mandan a los visitadores que cuando hagan informaciones no nombren a las mujeres, les mandan que digan solo que está amancebado con mujer que por su honestidad no se nombra. Les mandan también que en cualquier otra flaqueza que no sea pública se proceda así mismo para que se conserve la honra de las personas que vivan de este trato o entren en su casa o den lugar a hombres y mujeres sospechosas de cometer pecado ${ }^{17}$. Los sínodos también mandan que no haya alcahuetas o personas que vivan de este trato o entren en sus casas o den lugar a hombres y mujeres sospechosas para cometer pecados. Para evitar las ocasiones de las divinas ofensas en materia de incontinencia mandaban los jueces eclesiásticos poner en depósito en casas particulares a los complices principalmente a los indios y mestizos de lo que se origina una tácita servidumbre. XXIV

14 Sínodo de San Juan de Puerto Rico. Año 1645. Const. CLI; Const LIV; Const.

${ }^{15}$ Sínodo de San Juan de Puerto Rico. Año 1645. Const. XXXV.

${ }^{16}$ Sínodo de San Juan de Puerto Rico. Año 1645. Const. CLXXXIX.

${ }^{17}$ Sínodo de San Juan de Puerto Rico. Año 1645. Const. XIV.

"CUADERNOS DE ESTUDIOS GALLEGOS", Tomo XLI, Fascículo 106, Santiago 1993-94. 


\subsection{Trato que han de dispensar a los indios}

Los llantos de los miserables indios han llegado a oídos de Su Majestad quien viendo las ofensas de los pobres indios y las violencias que les hacen algunos encomenderos obligándoles a trabajar contra su voluntad más de lo que están obligados ${ }^{18}$. Conscientes de que se han seguido muertes de indios y negros en los trabajos de las pesquerías manda el sínodo que ningún indio libre sea llevado a dichas pesquerías contra su voluntad, que ninguna persona ocupe, molesta y haga trabajar a dichos indios contra su voluntad en ningún género de trabajos más que del que les está impuesto por los obispos gobernadores de estos reinos. Para que los indios se conserven y cesen las muertes se les impone bajo pena de 50 pesos y prohibe el trabajo de muchachos hasta haber cumplido los doce años ${ }^{19}$.

\subsection{Edificación de ermitas y erección de cofradías}

Ninguna persona puede edificar ermitas o capillas en ingenios, hatos, o corrales ni en otra parte sin licencia del obispo, ni demoler las ya erigidas bajo pena de excomunión mayor y treinta ducados. También les prohibe edificar iglesias y monasterios sin licencia de Su Majestad ${ }^{20}$. Algunos movidos de celo ordenan cofradías y hacen estatutos y por ello el sínodo manda que de aquí adelante no se haga ni se establezca cofradía alguna sin licencia del obispo, ni sin ella se hagan colectas ${ }^{21}$.

La oración de los cofrades es para que los santos con su protección nos auxilien en esta vida mortal. Se queja el sínodo de que se ha introducido una profanación tan irreverente en la fiesta que más parecen bacanales regocijos públicos y escándalo en el comercio de hombres y mujeres. Por ello manda que los curas no permitan hacer comedias ni corridas de toros ni otras diversiones profanas en las fiestas de dichas cofradías. Con el dinero recaudado entre los fieles no se pueden correr toros ni hacer comedias ni festivales profanos porque nada de esto es del servicio de Dios, ni de honra de los santos ${ }^{22}$. Esto se lo impone bajo pena de excomunión mayor y manda a los mayordomos no dispensen las entradas de las cofradías en comensaciones, hebriedades y otros desperdicios que fomentan los vicios ${ }^{23}$.

\footnotetext{
${ }^{18}$ Sínodo de San Juan de Puerto Rico. Año 1645. Const. XIV.

${ }^{19}$ Sínodo de San Juan de Puerto Rico. Año 1645. Const. XIV.

${ }^{20}$ Sínodo de Santiago de Chile. Año 1645. Const. XXIX.

${ }^{21}$ Sínodo de San Juan de Puerto Rico. Año 1681. Const. CI.

${ }^{22}$ Sínodo de San Juan de Puerto Rico. Año 1681. Const. CIII.

${ }^{23}$ Sínodo de Concepción de Chile. Año 1747. Const. II, Capt. VI.
} 


\subsection{Procesiones que mandan hacer los sínodos americanos}

Todos los cofrades tiene obligación de cuidar las procesiones de parroquias y rogaciones que se hacen en las iglesias. Le manda que en la del Corpus las letanías y demás que se hacen por cualquier necesidad de $\mathrm{Su}$ Majestad o prelado acudan con sus insignias y los sacristanes de las parroquias con sus cruces bajo pena de 10 pesos y los maestros de escuela envien sus niños a la procesión de letanías y rogaciones ${ }^{24}$. Prohibe que en la procesión del Corpus se hagan danzas de mujeres y las que haya sean de hombres y honestas y decentes. Esto se lo impone bajo pena de excomunión mayor ${ }^{25}$. También prohibe que salgan procesiones de noche en tiempo de cuaresma o por San Juan y que en las que se hicieren no salgan las mujeres de día ni de noche, ni anden vestidas de nazarenos cubiertos o descubiertos los rostros por la ocasión que hay de ofender a Dios. Esto se lo impone bajo pena de excomunión mayor y pena de diez ducados de multa $^{26}$.

\subsection{Obligaciones de los sacristanes}

Los sacristanes deben ser muy expertos, devotos y vigilantes en sus oficios, ser cuidadosos en tocar o hacer tocar al campanero las campanas a las horas señaladas por los sínodos. Al Ave María, darán nueve golpes de tres en tres con la campana mayor de modo que en la distancia de unos golpes a otros puedan rezar el Ave María. Esto será al anochecer. A las ocho en punto tocará a las ánimas para que todos hagan oración por los difuntos.

Cuando se alce la hostia y el cáliz en la misa mayor de cada día se hará señal con la campana grande para que los fieles donde se hallen puedan levantar el corazón a Dios y rezar algo. Tendrá cuidado de tañer las campanas por los difuntos para acordar a los vivos que han de morir.

\subsection{Ritos supersticiosos y adivinaciones}

El sínodo también condena los ritos supersticiosos cuando nos dice que no se reciban nuevas reliquias ni se admitan nuevos milagros si no fueron reconocidos y aprobados por el ordinario para que cesen todas las

\footnotetext{
${ }^{24}$ Sínodo de Santiago de Chile. Año 1681. Const. III, Libr. 3, Tít. 2.

${ }^{25}$ Sínodo de Santiago de Chile. Año 1681. Const. IV, Lib. II, Tít. 2.

${ }^{26}$ Sínodo de Santiago de Chile. Año 1681. Const. VIII, Lib. II, Tít. 2.
} 
supersticiones y abusos ${ }^{27}$. Les manda además que no tengan libros, oraciones, ni nóminas u otras cosas prohibidas por supersticiosas y malas. Les manda que ninguna persona de cualquier condición que sea haga nóminas ni las traiga consigo y quien las tuviere no use de ellas hasta que sean vistas por nos. Les exorta bajo pena de excomunión mayor y de diez ducados que cuando alguna cosa cause superstición por sus caracteres no conocidos o que provoquen risa dentro de 15 días se rompa. Manda que ninguno cure con ensalmos, no siendo primero vistos y examinados por nos ni use encantamientos, adivinanzas, hechicerías o supersticiones ni para saber lo que está por venir ni sobre cosas hurtadas, perdidas ni ocultas y que los saludadores no se admitan sin nuestra licencia ${ }^{28}$. Les manda también dar cuenta si hay algunas personas adivinas, hechiceras, brujas, conjuradoras de nublados o ensalmadores o que curen heridas o enfermedades con palabras supersticiosas encantadoras o que digan tener revelaciones o visiones o declaren las cosas por venir con embustes supersticio$\operatorname{sos}^{29}$.

\section{LAS MUJERES EN LOS SÍNODOS AMERICANOS}

Los sínodos con frecuencia hacen menciones referentes a las mujeres dado que en ellas quieren ver reflejada la pureza, la castidad, y la decencia de la sociedad. La preocupación y el deseo de los sínodos es que guarden la compostura las mujeres y esto les lleva a dar normas sobre su vestido y sobre su comportamiento dentro y fuera de las iglesias.

\subsection{Vestidos de las mujeres}

Los sínodos hacen ver la necesidad que tienen las mujeres de bajarse las basquiñas dado que es costumbre llevarlas altas, descubriendo ciertas profanidades. También les mandan que llevan cubiertos los brazos hasta el antebrazo por lo menos al salir de casa o cuando en ella tuvieren visi$\operatorname{tas}^{30}$. Su vestimenta al oír la misa debe completarse cubriendo la cabeza con un velo dado que antes lo hacían con una mantilla la cual solo debe

\footnotetext{
${ }^{27}$ Sínodo de San Juan de Puerto Rico. Año 1645. Const. CVIII.

${ }^{28}$ Sínodo de San Juan de Puerto Rico. Año 1645. Const. CXV.

${ }^{29}$ Sínodo de San Juan de Puerto Rico. Año 1645. Const. CLIX.

${ }^{30}$ Sínodo de Santiago de Chile. Año 1669 a 1763. Const. VIII, Tít. XX.
}

"CUADERNOS DE ESTUDIOS GALLEGOS", Tomo XLI, Fascículo 106, Santiago 1993-94. 
estar destinada a tapar el tallo y la cintura. La vestimenta de los indios era un modo de diferenciación social dado que nos dicen los sínodos que solo las plebeyas y las criadas tenían derecho a llevar mantilla con ribetes, terciopelo y sayas prohibiendo los mantos por ser prendas para damas ${ }^{31}$.

\subsection{Lugar de las mujeres en la iglesia}

Para que las mujeres no estén entre los hombres mientras se celebran los divinos misterios mandan los sínodos que dividan las iglesias parroquiales por la mitad y que en la parte más cercana del altar se sienten los hombres, y en la parte inferior se sienten las mujeres de modo que se evite el hablar y mirar unos a otros ${ }^{32}$. Por ser el lugar del presbiterio dedicado a los sacerdotes y ministros del altar no suban las mujeres ni se sienten en las tarimas de los altares por la irreverencia que de ello resulta ${ }^{33}$. A tal punto llega la concepción pecaminosa que el sínodo tiene de las mujeres que manda que ningún sacerdote secular o regular que no tenga 40 años de edad se le de licencia para confesar mujeres ${ }^{34}$.

La confesión debe administrarse con decencia y decoro. Los confesionarios para las mujeres deben tener reja. Si hubiere confesiones de noche tiene que haber luces en los altares.

\subsection{Salidas de noche}

No se permite en todo el obispado que las mulatas, negras libres, y esclavas salgan de sus casas habiendo anochecido a ganar jornales para sus amos por los pecados y amancebamientos públicos que de ello se siguen.

Mandan los sínodos a los dichos amos no permitan que las esclavas jornaleras vivan fuera de sus casas alquilándolas en la ciudad sino que las recojan de noche en las suyas para que debajo de sus amos y disciplina vivan honesta y religiosamente y se eviten los daños referidos ${ }^{35}$.

\subsection{Ocupaciones prohibidas a las mujeres}

Como el concurso de mujeres y hombres es peligroso a la salud de las

\footnotetext{
${ }^{31}$ Sínodo de Santiago de Chile. Año 1669 a 1763. Const. IV, Cap. 10

${ }^{32}$ Sínodo de San Juan de Puerto Rico. Año 1654. Const. II, Lib. 2.

${ }^{33}$ Sínodo de Concepción de Chile. Año 1747. Const. XIII, Capt. II.

${ }^{34}$ Sínodo de Santiago de Cuba. Año 1681. Const. V, Lib. IV, Tít. 4.

${ }^{35}$ Sínodo de Santiago de Cuba. Año 1681. Const. V, Lib. IV, Tít. 4.
} 
almas mandan los sínodos que de noche no se acompañe al santísimo sacramento cuando se lleve a los enfermos si no es en sus casas. Esto se lo prohibe bajo pena de excomunión mayor. También prohibe que en las reuniones o rosarios nocturnos que se hacen por devoción vayan hombres y mujeres mezclados ${ }^{36}$.

\subsection{Trato con viudas}

En algunos sitios es costumbre que las viudas no vayan a misa por mucho tiempo desde la muerte de su marido y cuando van, están sentadas al evangelio y hacen cosas que parece supersticiosa. Se ordena que los sacerdotes amonesten a las viudas, enseñandole que pecan no oyendo misa y cometiendo actos supersticiosos.

\section{FIESTAS Y DIVERSIONES PROHIBIDAS}

\subsection{Las vísperas de fiestas}

El sínodo manda que se preparen las fiestas no comiendo carne y ayunando el día antes. Prohibe velar en las iglesias las vísperas de fiestas de noche, pués lo que era servicio de Dios se trocó; el ayuno y la abstinencia en comidas y bebidas supérfluas, los cantares y loores divinos en cantares y pláticas profanas, la quietud y silencio en estrépito y ruído, la devoción y reverencia en profaneidad y por ello el sínodo manda que de aquí en adelante no se hagan tales votos ni de noche sean recibidos en las iglesias, ermitas, monasterios y hospitales hombres y mujeres y allí donde se acostumbre a hacer tales juntanzas los clérigos cierren las puertas antes que sea de noche bajo pena de seis pesos, y de doce a quienes velaren de noche ni se hagan en las iglesias, ayuntamientos, concejos, y otras juntanzas ${ }^{37}$.

El sínodo también manda bajo pena de excomunión mayor que en tañendo vísperas cesen los juegos, bailes y danzas en todo el lugar ${ }^{38}$.

\subsection{Juegos prohibidos en días de fiesta}

Por ser el juego ocasión de juntas perjudiciales y otros excesos y se mezclan en ellos supersticiones muy funestas y depravadas por ello el

\footnotetext{
${ }^{36}$ Sínodo de Concepción de Chile. Año 1747. Const. XIII, Capt. II.

${ }^{37}$ Sínodo de San Juan de Puerto Rico. Año 1645. Const. V.

${ }^{38}$ Sínodo de San Juan de Puerto Rico. Año 1645. Const. LXIX.
} 
sínodo manda a los curas, corregidores, encomendadores, mayordomos y demás gente que se sirve de indios no les permitan tales juegos entre si o con españoles y menos con indios por la mayor prostitución de la honestidad que se experimenta. Prohibe tales juegos en los días de fiesta porque ocasionan faltar a la misa cuando se hacen en partes distintas de las iglesias y por los inconvenientes que se experimentan cuando duran dos o tres días sucesivos y por el peligro de que pernocten gentes de ambos sexos en el campo.

\subsection{Trabajos prohibidos los días de fiesta}

Los sínodos mandan no trabajar en obras serviles dirigidas al interés temporal dedicándose al culto divino y provecho del alma y por ello no es lícito emprender viajes con mulas o carretas cargadas. En días de precepto los arrieros no levanten cargas ni inicien viajes bajo pena de cuatro pe$\operatorname{sos}^{39}$.

Todos los mercaderes y cajoneros de la ciudad no vendan cosa alguna de día o de noche en los días de fiesta, ni tengan sus puertas abiertas y sólo se les permite vender hasta las nueve azúcar y hierba que se tiene en este país como habitual para el mate. Todos los oficiales mecánicos eviten el trabajo. Manda que no entren ni salgan carretas ni se venda el forraje de mulas. Cuando ocurriese alguna causa para trabajar se debe pedir licencia al ordinario ${ }^{40}$.

Se prohibe mercado esos días y manda una y otra vez que no vendan en los días de fiesta ni tengan las tiendas abiertas bajo multa de cuatro pesos, que ninguna persona venda cosa comestible a las puertas de las iglesias, ni en los cementerios ni en las calles por donde pasan las procesiones bajo pena de excomunión mayor y de diez ducados a los libres y amos y prendimiento de las cosas que vendieren ${ }^{41}$.

\subsection{Bailes prohibidos}

El sínodo nos dice que los bailes torpes desonestos están prohibidos a causa de los pecados y escándalos que de ellos se siguen. Los visitadores mandan bajo pena de excomunión late sentenciae que ninguna persona haga ni de día ni de noche semejantes bailes en las casas ni consientan que

\footnotetext{
${ }^{39}$ Sínodo de Santiago de Chile. Año 1688 y 1766 . Const. I, Tít. XII.

${ }^{40}$ Sínodo de Santiago de Cuba. Año 1681. Const. VII, Capt. XV.

${ }^{41}$ Sínodo de San Juan de Puerto Rico. Año 1645. Const. CXXV.
} 
se hagan en los ingenios, estancias, hatos, corrales, campos y menos en las iglesias y cementerios ${ }^{42}$.

Sin licencia de los gobernadores no se consientan bailes a los indios y si se da que sea para bailes que sean de día en lugares y fiestas públicas.

Manda también el sínodo que no permitan que se junten hombres y mujeres para bailar mezclados y no den a los indios licencia para el expresado baile de noche o en lugares ocultos, sólo de día y con mucha moderación.

También prohibe a los españoles se mezclen con los indios a bailar o hagan estos bailes juntos con mujeres ${ }^{43}$. Les repite una y otra vez que si no es de orden del gobernador no se consientan bailes a los indios y para ello hace falta además la venia del cura y esta sólo se dará para bailes que se hagan de día ${ }^{44}$.

\subsection{Prohibición de faenas agrícolas}

Se prohibe trabajar en la agricultura y mandan los sínodos que tales días no se hagan rodeos de vacas.

\subsection{No representar comedias en las iglesias}

Para solemnizar la fiesta del Corpus Cristi y otras hay costumbre de hacer representaciones de comedias, danzas, autos, mascaradas y músicas a lo divino. El sínodo permite y tolera tal costumbre con tal que las comedias que se representen en las iglesias sean a lo divino y aprobadas por el ordinario y no mezclando en ellas entremeses y bailes ni otras cosas que atañen a todo género de deshonestidad y que no se haga dentro de las iglesias ${ }^{45}$.

El sínodo manda que en los ministerios dedicados al servicio de Dios no se mezclen profaneidades ni los lugares ni tiempos destinados para la oración y edificación de los fieles sean teatros de risa y vanidad.

Para librar de este pecado en este nuestro obispado mandamos que en las iglesias mientras se celebran los divinos oficios no intermedien representaciones o remembranzas profanas y prohiben el hacer pláticas de risa o donaires menospreciando la gravedad del lugar, eviten que en los miste-

\footnotetext{
${ }^{42}$ Sínodo de Santiago de Cuba. Año 1681. Const. VI, Lib. I, Tít. 12.

${ }^{43}$ Sínodo de Santiago de Chile. Año 1688 y 1763. Const. XXXII, Lib. 19.

${ }^{44}$ Sínodo de Santiago de Chile. Año 1688 y 1762. Const. XXXII, Tít. 19.

${ }^{45}$ Sínodo de San Juan de Puerto Rico. Año 1681. Const. LXIX.
} 
rios del culto de Dios se mezclen, para acabar con ello manda que no se consienta que en las iglesias, mientras se celebran oficios intermedien representaciones o remembranzas profanas y acabados los oficios sagrados hagan dar gracias dentro de la iglesia y les encomienda que quiten dicho abuso.

\subsection{Prohibición de lidiar toros}

Por el Motu Propio de Gregorio XI, están prohibidas las corridas de torneamientos y agitaciones de toros los días festivos ya que por estar dedicados al culto del Señor no deben profanarse con tales corridas ${ }^{46}$. El sínodo también prohibe lidiar toros a pie o a caballo bajo pena de excomunión mayor y prohibe bajo la misma pena las corridas de toros los días de fiesta. Son tantos los riesgos que ha habido en los toros que se juegan los días festivos que el sínodo se ve obligado a prohibir que en los domingos y días de fiesta se jueguen toros ni atados con sogas ni sueltos bajo pena de excomunión mayor y pérdida del toro aplicado su valor a los pobres de la cárcel ${ }^{47}$.

\footnotetext{
${ }^{46}$ Sínodo de Concepción de Chile. Año 1747. Const. XV, Ca XV.

${ }^{47}$ Sínodo de Santiago de Cuba. Año 1681. Const. V, Lib. II, Tít. 2.
}

"CUADERNOS DE ESTUDIOS GALLEGOS", Tomo XLI, Fascículo 106, Santiago 1993-94. 